\title{
INLAY BONE GRAFTING FOR NON-UNION OF THE SCAPHOID BONE BY THE ANTERIOR APPROACH*
}

\author{
B. J. Dooley, Melbourne, Australia
}

Non-union of fractures of the scaphoid bone usually results from failure to recognise or adequately to treat a fresh fracture. It is important to differentiate delayed union from established non-union. In the former, even if a year has elapsed since fracture, and even if the radiograph shows a wide cystic fracture line with or without avascular changes in the proximal fragment, union is still possible with immobilisation (Speed 1935, Wagner 1952, Stewart 1954). In established non-union, however, the fracture surfaces are sclerosed, and union is possible only after bone grafting. The decision to operate is made the more difficult because of the varying disability resulting from non-union of these fractures; with some it is very slight, with others it may be severe, particularly if the wrist is subjected to further injury or excessive use. The disability varies with the occupation of the patient; it is dependent also on the firmness of the fibrous union across the fracture site and its location in relation to the radial styloid process, as well as on the amount of local and general arthritic changes in the wrist joint. Barr, Elliston, Musnick, Delorne, Hanelin and Thibodeau (1953) found severe disability in every case of non-union, even without arthritic changes in the radiocarpal joint. In contrast, London (1961) found that non-union was seldom a cause of disability, and that patients presented only when further injury had aggravated the condition, which settled again with rest. It is generally agreed, however, that no wrist with an ununited fracture of the scaphoid bone can be classed as normal, or remain normal, until union of the fracture has occurred in good position and without avascular change in the bone or cartilage of the proximal fragment.

\section{SURGICAL APPROACHES AND RESULTS}

Soto-Hall and Haldeman (1941) exposed the fracture site through a dorsal incision, excised all the fibrous tissue of the pseudarthrosis and slotted one or two bone grafts across the fracture site.

Murray (1934) reported a method of bone grafting with drilling and bone pegging, and later (1946) reviewed 100 cases up to sixteen years after operation. Ninety-six had united and most had excellent function without signs of degeneration of the wrist joint. Using the same method Palmer and Widén in 1955 reported twenty-eight cases with union in all. Twenty of these cases had well established pseudarthroses.

Barnard and Stubbins (1948) combined bone pegging with removal of the radial styloid process. They believed that with styloidectomy the dorso-lateral approach was simplified and that there was less likelihood of secondary degenerative changes in the wrist at a later stage. They used bone from the excised radial styloid for the grafting. Union of the fracture was obtained in nine out of ten of their cases. Donaldson, Goodman, Rodrigues, Skovron and Gartland (1962) reported twenty-five cases treated by excision of the styloid process and bone pegging. These were done by several surgeons: in 76 per cent the fracture united and excellent function was restored.

Russe (1960), realising that the principal blood supply of the scaphoid bone entered its dorsal aspect, advocated an anterior approach using cancellous inlay grafts. He reported twenty successful operations in twenty-two cases of non-union.

* Paper read at the meeting of the Australian Orthopaedic Association in Sydney, October 1965. 


\section{BLOOD SUPPLY OF THE SCAPHOID BONE}

The blood supply of the scaphoid bone is from branches of the radial artery, which form a tenuous plexus of vessels on the narrow non-articular strip on the dorsum of the bone. The nutrient vessels penetrate the bone; most of the branches then travel towards the tuberosity, a few towards the proximal pole (Fig. 1) and one or two fine branches enter the volar surface of the bone. It should be emphasised that the dorsal plexus is tenuous and easily damaged when the bone is fractured. The nutrient vessels ramify in the cancellous bone and form a dense subchondral capillary bed in relation to the articular surfaces.

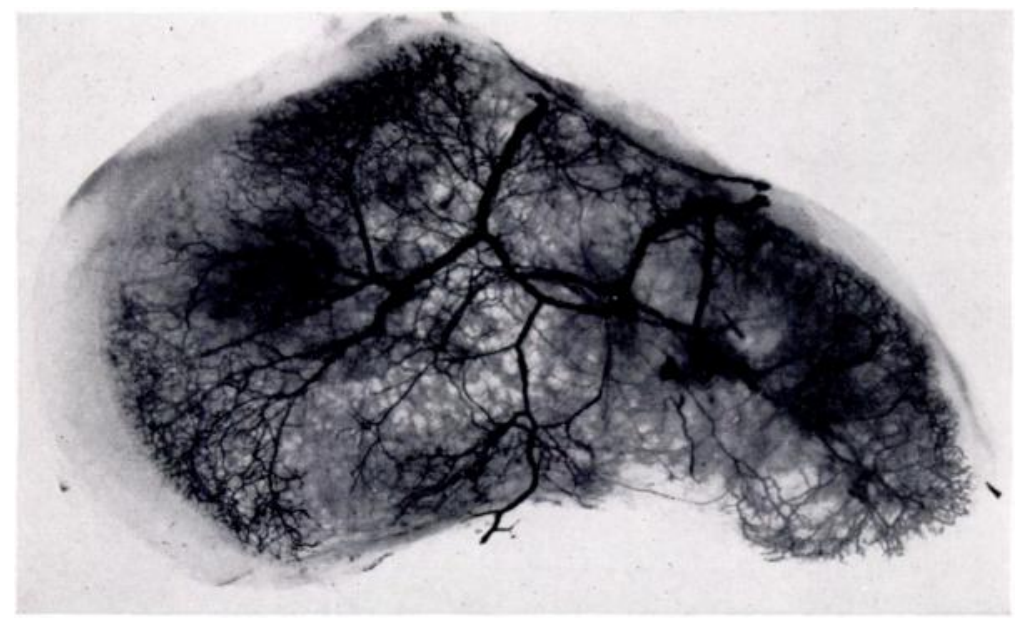

FIG. 1

Arterial supply of the scaphoid bone. A photograph of the left scaphoid bone from wrist of a boy of 13 years, prepared by the Spalteholz technique. The specimen has been so placed that the main vessels are shown entering the bone in the ligamentous area on the dorsal surface of the bone (above). One small vessel penetrates the volar aspect (below).

\section{CLINICAL MATERIAL}

During 1960 to 1964 twenty-three patients were selected for bone grafting for delayed or non-union of scaphoid fractures. Relative radiographic density of the proximal fragment was not considered a contra-indication to operation. Cases with the following features were considered unsuitable for grafting: 1) non-union of the scaphoid bone with established arthritic changes in the radiocarpal joint; and 2) severe avascular necrosis of the proximal fragment with collapse, resorption or fragmentation.

Table I gives details of the clinical material and Table II gives the time interval between fracture and operation. All cases with an interval of more than one and a half years had established non-union. All had had inadequate primary treatment, and all complained of disabling symptoms and difficulty in working because of aching and pain with weakness and stiffness of the wrist. In ten patients the interval between fracture and operation varied between six and eighteen months. Two of these presented nine months after an unrecognised fracture and the other eight patients had had plaster immobilisation for six months or more after recent fractures. The radiological appearances, after treatment for this duration, of a wide and cystic fracture line (with avascular change in the proximal pole in four cases) suggested that union with further plaster immobilisation alone was unlikely to occur, or, alternatively, that it would take an unduly long time.

\section{OPERATION}

The technique was that described by Russe (1960). Under general anaesthesia and tourniquet an anterior approach is made to the fracture site. A longitudinal incision 3 to 4

VOL. $50 \mathrm{~B}$, NO. 1, FEBRUARY 1968 
centimetres in length, starting from the flexor crease of the wrist and passing upwards is placed radial to the tendon of the flexor carpi radialis. The tendon is retracted to the ulnar side and the incision carried down through the capsule of the wrist to the fracture site, which is identified by moving the wrist. The nutrient vessels on the dorsum cannot be damaged in this approach. With a 3 to 4 millimetre gouge a hole is made in the non-articular part of the pseudarthrosis and excavated across the fracture surfaces well into the proximal and distal poles. If the gouge is fully rotated like a drill the bone is cored out of either fragment. A cavity is thus prepared with the least possible damage to the articular cartilage.

TABLE I

Clinical Material

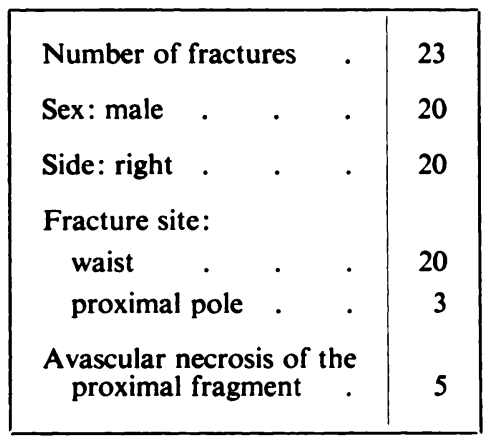

TABLE II

INTERVAL between Fracture and Operation

\begin{tabular}{|lll|l|}
\hline 6 to 18 months &. & $\cdot$ & 10 fractures \\
\hline $1 \frac{1}{2}$ to 6 years & $\cdot$ & $\cdot$ & 13 fractures \\
\hline
\end{tabular}

TABLE III

Average Time for Radiological Union after Operation

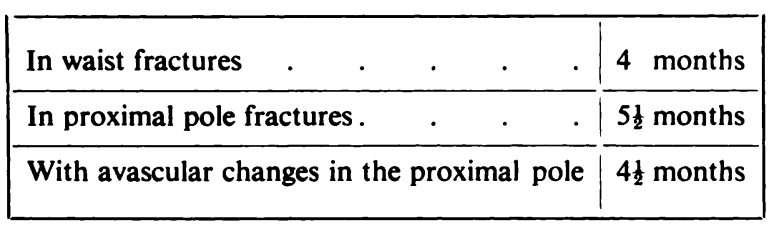

A piece of cancellous bone, about $2 \times 1 \times 1$ centimetres, is removed from the iliac crest together with small cancellous chips. The peg, after shaping, is placed into the cavity across the fracture site with the wrist held in dorsiflexion. The wrist is returned to neutral, and the graft is thereby firmly impacted. Multiple small chips are then packed into the cavity, completely obliterating it. The capsule and skin are sutured separately and a padded scaphoid plaster applied. This is changed to an unpadded plaster two weeks later. Plaster immobilisation is continued until radiological union is obtained.

After union, if the patient has to return to heavy work, a wrist gauntlet is worn for a further six months. 


\section{RESULTS}

Of the twenty-three patients operated on twenty achieved union after an average of four months' plaster immobilisation. When there was avascular necrosis of the proximal fragment or the fracture was in the proximal pole solid incorporation of the graft took longer (Table III, Figs. 2 to 9 ).

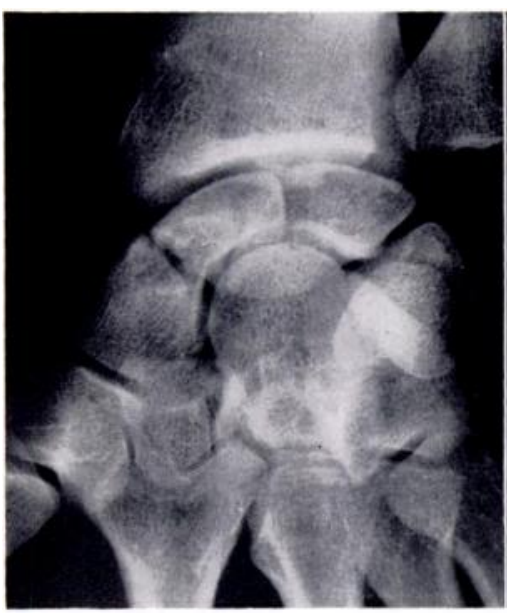

FIG. 2

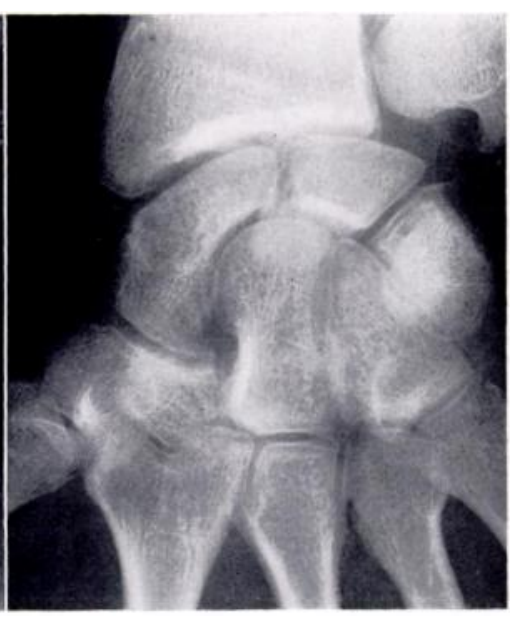

FIG. 3

Case 5-A successful result after a bone graft for non-union of two years duration in the scaphoid bone of a 19-year-old man. Figure 2-Before operation. Figure 3-Four months after operation.

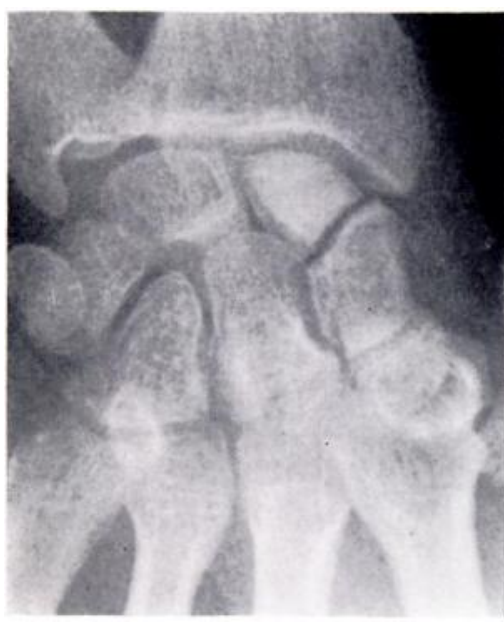

Fig. 4

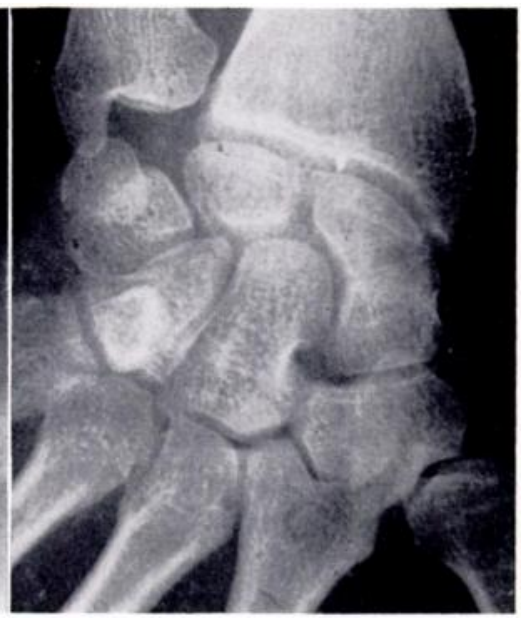

FIG. 5

Case 10 -Successful result in a 19-year-old motor mechanic who had sustained the fracture three years before. A very painful wrist developed four months before operation after a further injury: there was avascular necrosis of the proximal pole. Figure 4-Before operation. Figure 5-Three and a half months after operation.

All twenty patients after successful grafts returned to their previous occupations. Seventeen were subjects of compensation and none has claimed for a permanent disability.

One patient (Case 2) fell and refractured the scaphoid bone three months after removal of plaster after a successful bone graft. The fracture united solidly after a further three months in plaster.

Three patients had fractures through the proximal pole (Cases $7,9,12)$. These united, two with excellent results; the other (Case 12, Figs. 6 and 7) was a champion tennis player 


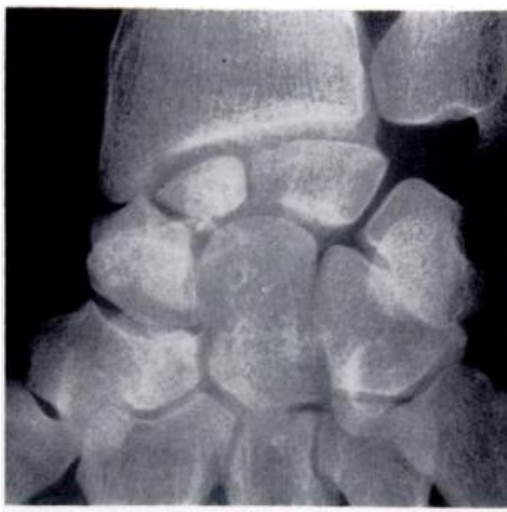

Fig. 6

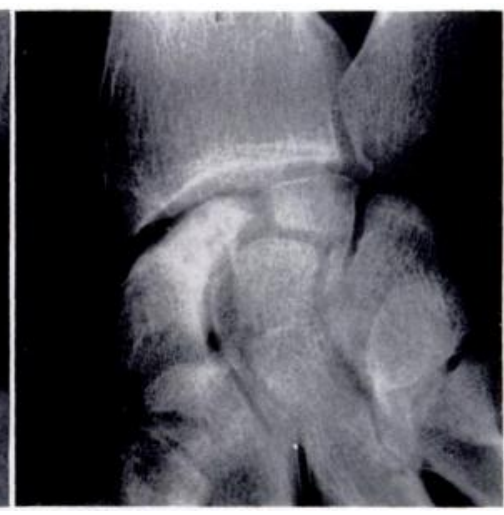

FIG. 7

Case 12-A pseudarthrosis of three years duration in the proximal pole of scaphoid bone of a 20-year-old champion tennis player. Figure 6-Before operation. Figure 7-Six months after operation. Union has occurred but with avascular necrosis of proximal fragment.

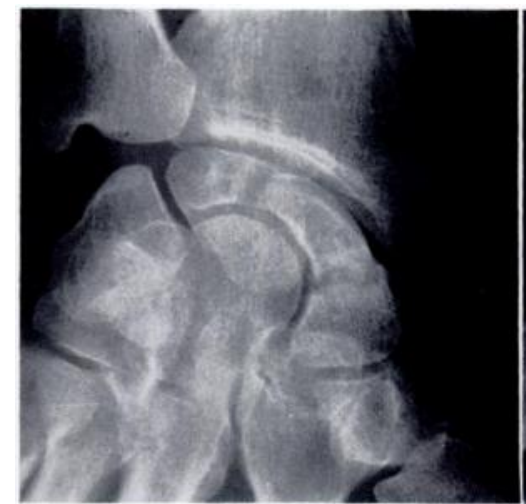

Fig. 8

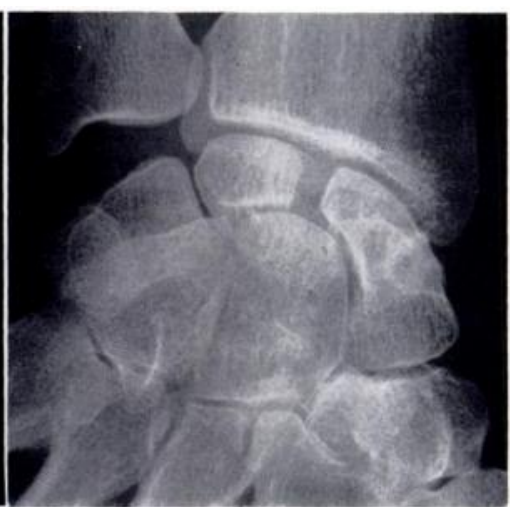

FIG. 9

Case 13-A fracture of one and a half years duration in a 20-year-old electrician. Figure 8-Before operation. Figure 9-Three and a half months after operation.

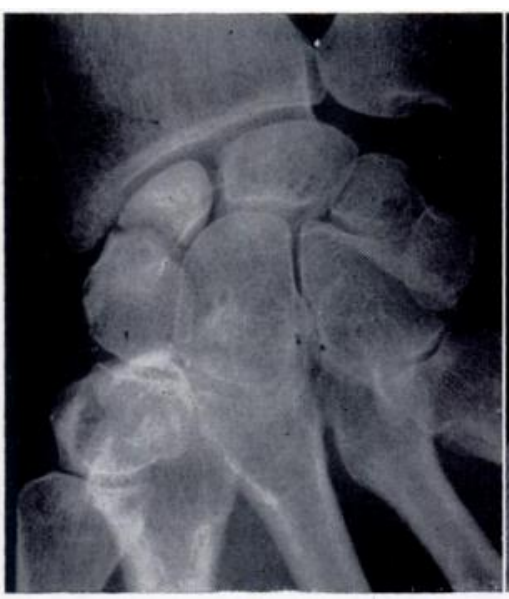

FIG. 10

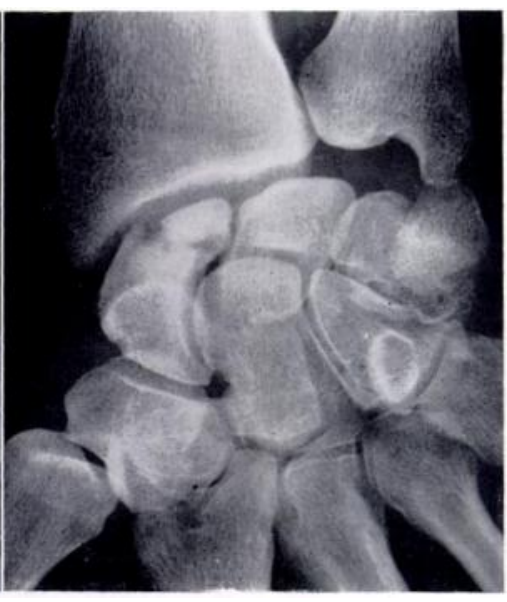

Fig. 11

Case 23-An unsuccessful result in a 22-year-old labourer with a fracture of two years duration. Figure 10-Before operation. Figure 11-One year after operation. The function was good, but there has been collapse and avascular change in the proximal fragment, but apparently the bone graft is incorporated. 
TABLE IV

Summary of Case Histories

\begin{tabular}{|c|c|c|c|c|c|c|c|c|}
\hline $\begin{array}{c}\text { Case } \\
\text { number }\end{array}$ & $\begin{array}{c}\text { Age } \\
(\text { years })\end{array}$ & Sex & Side & Occupation & $\begin{array}{c}\text { Conservative treatment } \\
\text { and comments }\end{array}$ & $\begin{array}{c}\text { Interval } \\
\text { between } \\
\text { fracture and } \\
\text { operation }\end{array}$ & $\begin{array}{l}\text { Time to union } \\
\text { after operation }\end{array}$ & Function \\
\hline 1 & 26 & $\mathbf{M}$ & $\mathbf{L}$ & Farmer & None & $1 \frac{1}{2}$ years & $3 \frac{1}{2}$ months & Good \\
\hline 2 & 37 & $\mathrm{~F}$ & $\mathbf{R}$ & Machinist & None & 9 months & 4 months & $\begin{array}{c}\text { Excellent. } \\
\text { Fell three months } \\
\text { later; refractured; } \\
\text { united after } \\
\text { three months }\end{array}$ \\
\hline 3 & 38 & $\mathbf{M}$ & $\mathbf{R}$ & Labourer & Three months in plaster & $1 \frac{1}{2}$ years & Non-union & Poor \\
\hline 4 & 23 & $\mathbf{M}$ & $\mathbf{R}$ & Bricklayer & Six months in plaster & 6 months & 4 months & Excellent \\
\hline 5 & 19 & $\mathbf{M}$ & $\mathbf{R}$ & Fitter & None & 2 years & 4 months & Excellent \\
\hline 6 & 22 & $\mathbf{M}$ & $\mathbf{L}$ & Labourer & 6 weeks in plaster & $1 \frac{1}{2}$ years & 4 months & Excellent \\
\hline 7 & 42 & $\mathbf{M}$ & $\mathbf{L}$ & Carpenter & $\begin{array}{l}\text { Six months in plaster. } \\
\text { Proximal pole fracture } \\
\text { and avascular necrosis }\end{array}$ & 6 months & 6 months & Excellent \\
\hline 8 & 27 & $\mathbf{M}$ & $\mathbf{R}$ & Labourer & None & $1 \frac{1}{2}$ years & 4 months & Excellent \\
\hline 9 & 41 & $\mathbf{F}$ & $\mathbf{R}$ & Barmaid & $\begin{array}{l}\text { Six months in plaster. } \\
\text { Proximal pole fracture }\end{array}$ & 6 months & $4 \frac{1}{2}$ months & Excellent \\
\hline 10 & 19 & $\mathbf{M}$ & $\mathbf{R}$ & $\begin{array}{l}\text { Motor } \\
\text { mechanic }\end{array}$ & $\begin{array}{l}\text { Six months in plaster. } \\
\text { Avascular necrosis }\end{array}$ & 3 years & $3 \frac{1}{2}$ months & Good \\
\hline 11 & 17 & $\mathbf{M}$ & $\mathbf{R}$ & Student & None & 2 years & $3 \frac{1}{2}$ months & Excellent \\
\hline 12 & 20 & $\mathbf{M}$ & $\mathbf{R}$ & $\begin{array}{l}\text { Tennis } \\
\text { player }\end{array}$ & $\begin{array}{l}\text { Six weeks in plaster. } \\
\text { Proximal pole fracture }\end{array}$ & 3 years & 6 months & $\begin{array}{c}\text { Fair. } \\
\begin{array}{c}\text { Avascular necrosis } \\
\text { of proximal pole }\end{array}\end{array}$ \\
\hline 13 & 20 & $\mathbf{M}$ & $\mathbf{R}$ & Electrician & None & $1 \frac{1}{2}$ years & $3 \frac{1}{2}$ months & Good \\
\hline 14 & 44 & $\mathbf{M}$ & $\mathbf{R}$ & $\begin{array}{l}\text { Boiler- } \\
\text { maker }\end{array}$ & $\begin{array}{l}\text { Six months in plaster. } \\
\text { Avascular necrosis }\end{array}$ & 6 months & 6 months & Excellent \\
\hline 15 & 20 & $\mathbf{M}$ & $\mathbf{R}$ & $\begin{array}{l}\text { Apprentice } \\
\text { plumber }\end{array}$ & None & 6 years & 4 months & Good \\
\hline 16 & 20 & $\mathbf{M}$ & $\mathbf{R}$ & Farmer & None & 9 months & $3 \frac{1}{2}$ months & Excellent \\
\hline 17 & 30 & $\mathbf{M}$ & $\mathbf{R}$ & Labourer & $\begin{array}{c}\text { No treatment for } \\
\text { three months. } \\
\text { Plaster for six months }\end{array}$ & 9 months & $3 \frac{1}{2}$ months & Excellent \\
\hline 18 & 35 & $\mathbf{M}$ & $\mathbf{R}$ & Labourer & $\begin{array}{l}\text { Six months in plaster. } \\
\text { Avascular necrosis }\end{array}$ & 6 months & $3 \frac{1}{2}$ months & Excellent \\
\hline 19 & 23 & $\mathbf{M}$ & $\mathbf{R}$ & Plumber & Three months initially & 3 years & 6 months & Excellent \\
\hline 20 & 17 & $\mathbf{F}$ & $\mathbf{R}$ & $\begin{array}{l}\text { Press } \\
\text { operator }\end{array}$ & Four weeks in plaster & 2 years & $3 \frac{1}{2}$ months & $\begin{array}{l}\text { Fair. } \\
\text { Avascular changes } \\
\text { at proximal pole }\end{array}$ \\
\hline 21 & 40 & $\mathbf{M}$ & $\mathbf{R}$ & Farmer & $\begin{array}{l}\text { One year in plaster. } \\
\text { Avascular necrosis }\end{array}$ & 1 year & Non-union & Poor \\
\hline 22 & 17 & $\mathbf{M}$ & $\mathbf{R}$ & Fitter & None & 2 years & 4 months & Good \\
\hline 23 & 22 & $\mathbf{M}$ & $\mathbf{R}$ & Labourer & None & 2 years & $\begin{array}{c}\text { Non-union } \\
\text { at } 6 \text { months } \\
\text { after operation }\end{array}$ & Good \\
\hline
\end{tabular}


up to the time of fracture of the right scaphoid bone. He was unable to play for the next three years because of a painful pseudarthrosis. After bone grafting he has returned to tennis and squash. The wrist is strong with only a minor ache on extreme stress, but the radiograph shows collapse and avascular necrosis of the proximal fragment.

The three cases of persistent non-union after operation were interesting. One patient (Case 3) appeared to have slight subluxation of the lunate, although not a true trans-scaphoid perilunar dislocation of the wrist. In 1962 he had been treated for a fresh fracture of the waist of the scaphoid bone and after three months in plaster the fracture appeared to unite. The follow-up was inadequate and he presented fifteen months later with non-union. Grafting was advised. The only unusual feature at operation was the free mobility of the fragments. The pseudarthrosis failed to unite after four and a half months and he declined further immobilisation. He has sought compensation for a permanent disability. The second case (Case 21) was of a forty-one-year-old farmer with a one-year-old fracture, treated in plaster for this period, complicated by avascular necrosis of the proximal fragment. In the third case (Case 23, Figs. 10 and 11) immobilisation was continued for six months after operation. The fracture was still ununited and there was resorption of the proximal fragment. The graft, however, appeared incorporated and function was good.

Functional results-The follow-up is of only five years, and hence too short to assess the ultimate functional and radiological results, particularly with regard to later degenerative

TABLE V

Functional ReSUltS

\begin{tabular}{|l|l|}
\hline Excellent & 13 \\
Good. & $6(1$ with non-union $)$ \\
Fair or poor & $\begin{array}{r}4(2 \text { with non-union, } \\
\text { 2 with avascular changes } \\
\text { in the proximal pole })\end{array}$ \\
\hline
\end{tabular}

changes of the wrist joint. Function was considered excellent if the patient had a painless strong wrist and there was only very slight limitation of movement. Function was considered fair or poor if the patient complained of aching, weakness or much stiffness in the wrist (Table V).

\section{DISCUSSION AND CONCLUSIONS}

Cancellous inlay bone grafting for delayed union or non-union of the scaphoid bone gives good results in most cases (Table IV). The operation is easy, does not require radiological control and does not damage the dorsal arterial plexus. The indications for the operation are twofold: firstly for patients complaining of disabling symptoms in the wrist joint with an established pseudarthrosis of the scaphoid bone, with neither arthritic changes nor severe avascularity of the proximal fragment; and, secondly, for delayed union in recent fractures despite adequate immobilisation. Union may still occur if conservative treatment is continued further, but because this may take up to eighteen months (during which time most patients would be unable to work), operation is a reasonable alternative.

In this series two scaphoid fractures united after operation with some collapse of the proximal fragment. This probably resulted from removal of too much bone (preliminary to inlaying the graft) from an already small fragment with a poor blood supply.

The operation can be performed even in the presence of a small proximal fragment and gave a satisfactory result in two out of three such cases.

I should like to thank $\mathrm{Mr} \mathrm{H}$. Crock for his help in the preparation of this paper. 


\section{REFERENCES}

Barnard, L., and Stubins, S. G. (1948): Styloidectomy of the Radius in the Surgical Treatment of Non-union of the Carpal Navicular. Journal of Bone and Joint Surgery, 30-A, 98.

Barr, J. S., Elliston, W. A., Musnick, H., Delorme, T. L., Hanelin, J., and Thibodeau, A. A. (1953): Fracture of the Carpal Navicular (Scaphoid) Bone. Journal of Bone and Joint Surgery, 35-A, 609.

Donaldson, W. F., Jun., Goodman, M. C., Rodriguez, E. E., Skovron, M., and Gartland, J. J. (1962): Evaluation of Treatment for Non-union of the Carpal Navicular. Journal of Bone and Joint Surgery, 44-A, 169.

London, P. S. (1961): The Broken Scaphoid Bone. Journal of Bone and Joint Surgery, 43-B, 237.

MuRRAY, G. (1934): Bone-graft for Non-union of the Carpal Scaphoid. British Journal of Surgery, 22, 63.

Murray, G. (1946): End Results of Bone-grafting for Non-union of the Carpal Navicular. Journal of Bone and Joint Surgery, 28, 749.

Palmer, I., and Widén, A. (1955): Treatment of Fractures and Pseudarthrosis of the Scaphoid with Central Grafting (Autogenous Bone-peg). Acta Chirurgica Scandinavica, 110, 206.

Russe, O. (1960): Fracture of the Carpal Navicular. Journal of Bone and Joint Surgery, 42-A, 759.

Soto-Hall, R., and Haldeman, K. O. (1941): The Conservative and Operative Treatment of Fractures of the Carpal Scaphoid (Navicular). Journal of Bone and Joint Surgery, 23, 841.

SPEed, K. (1935): Fractures of the Carpus. Journal of Bone and Joint Surgery, 17, 965.

Stewart, M. J. (1954): Fractures of the Carpal Navicular (Scaphoid). Journal of Bone and Joint Surgery, 36-A, 998.

Wagner, C. J. (1952): Fractures of the Carpal Navicular. Journal of Bone and Joint Surgery, 34-A, 774. 